Acta Crystallographica Section D

Biological Crystallography

ISSN 0907-4449

Nicolas Tarbouriech, ${ }^{\text {a,b }}$ Marlyse Buisson, ${ }^{b, c}$ Thibault Géoui, ${ }^{a, b}$ Susan Daenke, ${ }^{\mathrm{d}}$ Stephen Cusack $^{\mathrm{a}}$ and Wim Pascal Burmeister ${ }^{b, e} *$

${ }^{a}$ EMBL-Grenoble Outstation, BP 181, F-38042 Grenoble CEDEX 9, France, ${ }^{\mathbf{b}}$ Institut de Virologie Moléculaire et Structurale, FRE 2854 CNRS-UJF, BP 181, F-38042 Grenoble CEDEX 9, France, 'Laboratoire de Virologie, CHU Michallon, BP 217, F-38043 Grenoble CEDEX 9, France, 'Wellcome Trust Centre for Human Genetics, University of Oxford, Oxford OX3 7BN, England, and $\mathbf{e}_{\text {Institut }}$ Universitaire de France, 103 Boulevard

Saint-Michel, F-75005 Paris, France

Correspondence e-mail: wpb@embl-grenoble.fr

\title{
Structural genomics of the Epstein-Barr virus
}

Epstein-Barr virus is a herpesvirus that causes infectious mononucleosis, carcinomas and immunoproliferative disease. Its genome encodes 86 proteins, which provided targets for a structural genomics project. After updating the annotation of the genome, 23 open reading frames were chosen for expression in Escherichia coli, initially selecting for those with known enzyme activity and then supplementing this set based on a series of predicted properties, in particular secondary structure. The major obstacle turned out to be poor expression and low solubility. Surprisingly, this could not be overcome by modifications of the constructs, changes of expression temperature or strain or renaturation. Of the eight soluble proteins, five were crystallized using robotic nanolitredrop crystallization trials, which led to four solved structures. Although these results depended on individual treatment rather than standardized protocols, a high-throughput miniaturized crystallization screening protocol was a key component of success with these difficult proteins.

\section{Introduction}

Human herpesviruses comprise three subfamilies: (i) $\alpha$-herpesviruses [herpes simplex viruses (HSV) 1 and 2 and varicella zoster virus (VZV)], (ii) $\beta$-herpesviruses [cytomegalovirus (CMV) and human herpesvirus (HHV) 6 and 7] and (iii) $\gamma$-herpesviruses, comprising the Kaposi's sarcomaassociated herpesvirus (KSHV or HHV8) and Epstein-Barr virus (EBV or HHV4). The last infects the vast majority of the world's human population, establishing and maintaining a lifelong persistence in the infected host.

Primary infection typically occurs in childhood and is frequently asymptomatic. In contrast, a delayed primary infection in adolescents or young adults results in infectious mononucleosis (IM) in approximately half of cases, with symptoms including fever, pharyngitis, lymphadenopathy and splenomegaly. IM is a self-limiting lymphoproliferative disorder characterized by an expansion of EBV-infected B-lymphocytes associated with viral lytic replication in the oropharynx, controlled by a vigorous $\mathrm{CD}^{+}$cytotoxic T-cell immune response. The majority of cases of acute IM recover, but serious complications can occasionally lead to death. EBV is associated with a number of cancers in the immunocompetent host (Rickinson \& Kieff, 1996), in particular Burkitt's lymphoma and nasopharyngeal carcinoma, which are endemic in African and Asian populations (Raab-Traub, 2005). Furthermore, EBV can lead to immunoproliferative disease in immunosuppressed patients, notably those infected with HIV (Rickinson \& Kieff, 1996). Currently licensed antiherpesvirus drugs (acyclovir and related compounds) directed against viral DNA synthesis (Coen \& Schaffer, 2003) show little effect against EBV.
Received 15 November 2005 Accepted 1 August 2006 


\section{Table 1}

Proteins of EBV.

Accession, SwissProt, TrEMBL or PIR (Protein Information Resource) accession number. NCBI, GI numbers assigned by NCBI. Function, information on name, synonyms and function of the protein. ORF EBV, name of the EBV open reading frame. F, classification based on the function into C, capsid; M, membrane (glyco)protein; N, nucleotide metabolism; L, latency; P, packaging; R, replication; S, transcription factors, transactivators, signalling; T, tegument. S, an $\times$ means translated from spliced messenger RNA. Occ., occurrence in herpesvirus subfamilies, no entry for proteins present only in EBV and very closely related viruses such as rhesus lymphocryptovirus (LCV). Homologue, name of the homologue in HSV, if existing, otherwise of human CMV. $N$, number of constructs used in the project. St, current status. Proteins with enzymatic activity are shown in bold. For space reasons, only a limited number of references to original work are given; otherwise, review articles are cited. The annotation extensively used the BLAST program at NCBI (Altschul et al., 1997).

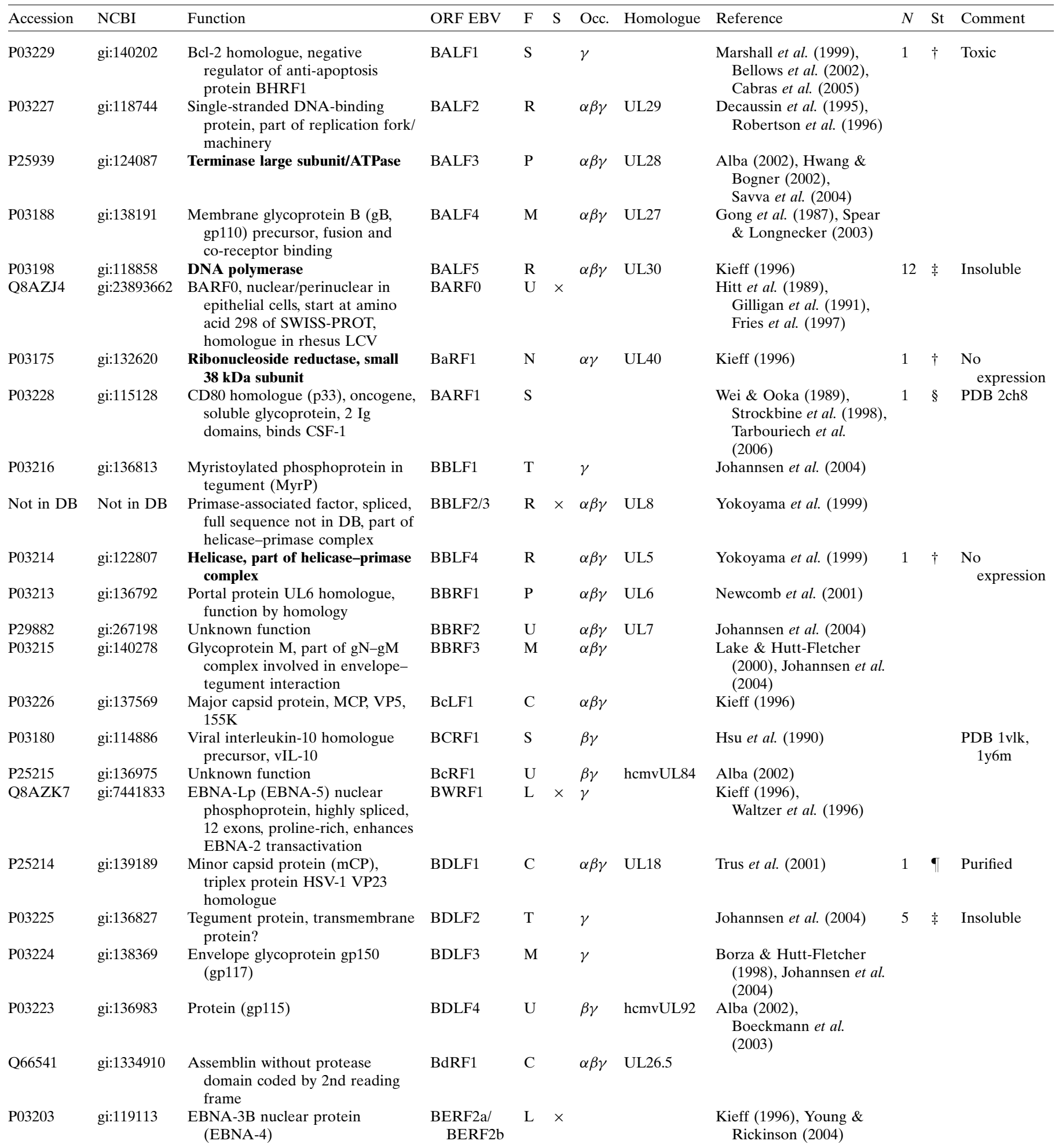


Table 1 (continued)

\begin{tabular}{|c|c|c|c|c|c|c|c|c|c|c|c|}
\hline Accession & NCBI & Function & ORF EBV & $\mathrm{F}$ & $\mathrm{S}$ & Occ. & Homologue & Reference & $N$ & St & Comment \\
\hline P03204 & gi:119114 & $\begin{array}{l}\text { EBNA-3C nuclear protein } \\
\text { (EBNA-6, EBNA-4B) (-) effect } \\
\text { on transactivation, EBNA-2 and } \\
\text { cell cycle, essential for } \\
\text { immortalization }\end{array}$ & $\begin{array}{l}\text { BERF3/ } \\
\text { BERF4 }\end{array}$ & $\mathrm{L}$ & $x$ & & & $\begin{array}{l}\text { Kieff (1996), Young \& } \\
\text { Rickinson (2004) }\end{array}$ & & & \\
\hline P03184 & gi:136878 & $\begin{array}{l}\text { Role in DNA packaging, cytosolic } \\
\text { zinc-binding protein, cysteine- } \\
\text { rich }\end{array}$ & BFLF1 & $\mathrm{P}$ & & $\alpha \beta \gamma$ & UL32 & Chang et al. (1996) & & & \\
\hline P03183 & gi:136873 & $\begin{array}{l}\text { Nuclear membrane } \\
\text { phosphoprotein, part of intra- } \\
\text { cellular virions, egress protein, } \\
\text { complex with BFRF1 }\end{array}$ & BFLF2 & M & & $\alpha \beta \gamma$ & UL31 & $\begin{array}{l}\text { Lake \& Hutt-Fletcher } \\
\text { (2004), Gonnella et al. } \\
\quad(2005)\end{array}$ & 2 & $\neq$ & Insoluble \\
\hline P03185 & gi:136886 & $\begin{array}{l}\text { Nuclear membrane protein p38, } \\
\text { transmembrane with large } \\
\text { cytoplasm domain, complex with } \\
\text { BFLF2 }\end{array}$ & BFRF1 & M & & $\beta \gamma$ & hcmvUL50 & $\begin{array}{l}\text { Lake \& Hutt-Fletcher } \\
\qquad(2004)\end{array}$ & & & \\
\hline P14347 & gi:140660 & $\begin{array}{l}\text { Unknown function, not included in } \\
\text { virions }\end{array}$ & BFRF2 & $\mathrm{U}$ & & $\beta \gamma$ & hcmvUL49 & $\begin{array}{l}\text { Bellows et al. }(2002) \\
\quad \text { Johannsen } \text { et al. }(2004)\end{array}$ & & & \\
\hline P14348 & gi:139195 & $\begin{array}{l}\text { Smallest capsid protein (sCP) on } \\
\text { outer capsid surface, } \\
\text { HSV1-VP26 homologue, KSHV } \\
\text { ORF } 65 \text { homologue }\end{array}$ & BFRF3 & $\mathrm{C}$ & & $\alpha \beta \gamma$ & UL35 & $\begin{array}{l}\text { Nealon et al. (2001), } \\
\text { Bowman et al. }(2003) \text {, } \\
\text { Johannsen et al. }(2004)\end{array}$ & & & \\
\hline AAA45868 & gi:330334 & $\begin{array}{l}\text { DNA-cleavage and packaging } \\
\text { protein, part of the DNA- } \\
\text { packaging machinery } \\
\text { (BFRF0.5, HS4BAM) }\end{array}$ & BFRF4 & $\mathrm{P}$ & & $\alpha \beta \gamma$ & UL33 & $\begin{array}{l}\text { Alba (2002), } \\
\text { Beard \& Baines (2004) }\end{array}$ & & & \\
\hline P03222 & gi:136833 & Tegument protein (gp115) & BGLF1 & $\mathrm{T}$ & & $\gamma$ & & Johannsen et al. (2004) & 1 & 末 & Insoluble \\
\hline P03221 & gi:114952 & Tegument protein, MyrPBP & BGLF2 & $\mathrm{T}$ & & $\alpha \beta \gamma$ & UL16 & $\begin{array}{l}\text { Boeckmann et al. (2003), } \\
\text { Johannsen } \text { et al. }(2004)\end{array}$ & & & \\
\hline P03220 & gi:136988 & $\begin{array}{l}\text { Homologue to HSV-1 tegument } \\
\text { protein, but not included in } \\
\text { virion, gp118 }\end{array}$ & BGLF3 & $\mathrm{U}$ & & $\alpha \beta \gamma$ & UL14 & Johannsen et al. (2004) & & & \\
\hline P13288 & gi:125627 & $\begin{array}{l}\text { Ser/Thr kinase, phosphorylation of } \\
\text { nucleoside analogues, tegument } \\
\text { protein }\end{array}$ & BGLF4 & $\mathrm{N}$ & & $\alpha \beta \gamma$ & UL13 & $\begin{array}{l}\text { Smith \& Smith (1989), } \\
\text { Marschall } \text { et al. }(2002) \text {, } \\
\text { Johannsen } \text { et al. }(2004)\end{array}$ & 4 & $\ddagger$ & Insoluble \\
\hline P03217 & gi:119691 & $\begin{array}{l}\text { Alkaline exonuclease, involved } \\
\text { together with BALF2 in DNA } \\
\text { recombination }\end{array}$ & BGLF5 & $\mathrm{R}$ & & $\alpha \beta \gamma$ & UL12 & $\begin{array}{l}\text { Cheng et al. (1980), } \\
\text { Reuven et al. (2004) }\end{array}$ & & & \\
\hline P03219 & gi:23893636 & $\begin{array}{l}\text { DNA-packaging protein, } \\
\text { terminase small subunit }\end{array}$ & $\begin{array}{l}\text { BGRF1/ } \\
\text { BDRF1 }\end{array}$ & $\mathrm{P}$ & $x$ & $\alpha \beta \gamma$ & UL15 & Alba (2002) & & & \\
\hline P03181 & gi:140778 & $\begin{array}{l}\text { Proline-rich protein LF3, unknown } \\
\text { function, tandem repeats, NotI } \\
\text { repeat ( } 125 \mathrm{bp}) \text {, homologue in } \\
\text { rhesus LCV }\end{array}$ & BHLF1 & $\mathrm{U}$ & & & & $\begin{array}{l}\text { Laux et al. }(1985) \text {, } \\
\text { Rivailler } \text { et al. }(2002), \\
\text { Farell (2005) }\end{array}$ & & & \\
\hline P03182 & gi:119102 & $\begin{array}{l}\text { Anti-apoptotic factor bcl-2 homo- } \\
\text { logue, early antigen protein R } \\
\text { (EA-R), nuclear antigen }\end{array}$ & BHRF1 & $\mathrm{S}$ & & $\gamma$ & & Huang et al. (2003) & 2 & $\dagger$ & $\begin{array}{l}\text { PDB 1q59 } \\
\text { (NMR) }\end{array}$ \\
\hline P03208 & gi:138777 & $\begin{array}{l}\text { G-protein coupled receptor } \\
\text { (G-PCR), } 7 \text { transmembrane } \\
\text { helices, } 6 \text { glycosylation sites, } \\
2 \text { disulfide bridges gP64 }\end{array}$ & BILF1 & M & & $\gamma$ & & $\begin{array}{l}\text { Hutt-Fletcher (2005), } \\
\text { Paulsen et al. (2005) }\end{array}$ & & & \\
\hline P03218 & gi:138183 & $\begin{array}{l}\text { Membrane glycoprotein gp55/80, } \\
\text { Ig-like, gp78 }\end{array}$ & BILF2 & M & & & & $\begin{array}{l}\text { Mackett et al. }(1990) \text {, } \\
\text { Boeckmann } \text { et al. } \\
\text { (2003), Johannsen et al. } \\
\text { (2004) }\end{array}$ & & & \\
\hline P03211 & gi:119110 & $\begin{array}{l}\text { Latent nuclear protein EBNA-1, } \\
\text { assures EBV episome } \\
\text { maintenance replication, } \\
\text { Gly-rich domain, essential for } \\
\text { immortalization }\end{array}$ & BKRF1 & $\mathrm{L}$ & & & & Bochkarev et al. (1996) & & & $\begin{array}{l}\text { PDB 1b3t, } \\
\text { 1vhi }\end{array}$ \\
\hline $\mathrm{P} 03212$ & gi:140976 & $\begin{array}{l}\text { Glycoprotein L precursor, gp } 25 \text {, in } \\
\text { gL-gH complex involved in viral } \\
\text { fusion together with } \mathrm{gB}\end{array}$ & BKRF2 & M & & $\alpha \beta \gamma$ & UL1 & $\begin{array}{l}\text { Hutt-Fletcher (2005), } \\
\text { Spear \& Longnecker } \\
(2003)\end{array}$ & & & \\
\hline P12888 & gi:137034 & Uracil-DNA glycosylase & BKRF3 & $\mathrm{N}$ & & $\alpha \beta \gamma$ & UL2 & $\begin{array}{l}\text { Winters \& Williams } \\
\text { (1993) }\end{array}$ & 10 & $\S$ & $\begin{array}{r}\text { Publication in } \\
\text { preparation }\end{array}$ \\
\hline P30117 & gi:267499 & Tegument phosphoprotein & BKRF4 & $\mathrm{T}$ & & $\gamma$ & & Johannsen et al. (2004) & & & \\
\hline P03200 & gi:138368 & $\begin{array}{l}\text { Envelope glycoprotein gp350 } \\
\text { (gp340) initial cell binding } \\
\text { through complement receptor } 2\end{array}$ & BLLF1 & M & & $\alpha \gamma$ & & $\begin{array}{l}\text { Spear \& Longnecker } \\
\quad(2003), \text { Hutt-Fletcher } \\
(2005)\end{array}$ & & & \\
\hline
\end{tabular}


Table 1 (continued)

\begin{tabular}{|c|c|c|c|c|c|c|c|c|c|c|c|}
\hline Accession & NCBI & Function & ORF EBV & $\mathrm{F}$ & S & Occ. & Homologue & Reference & $N$ & St & Comment \\
\hline AAA45880 & gi:330361 & $\begin{array}{l}\text { Envelope glycoprotein gp } 220, \\
\text { obtained through in-frame } \\
\text { splicing from BLLF1 }\end{array}$ & BLLF1b & M & $\times$ & $\alpha \gamma$ & & Beisel et al. (1985) & & & \\
\hline P03199 & gi:140999 & Unknown function & BLLF2 & $\mathrm{U}$ & & $\gamma$ & & & & & \\
\hline P03195 & gi:118952 & dUTP pyrophosphatase, dUTPase & BLLF3 & $\mathrm{N}$ & & $\alpha \gamma$ & UL50 & $\begin{array}{l}\text { Sommer et al. }(1996) \text {, } \\
\text { Tarbouriech et al. } \\
\text { (2005) }\end{array}$ & 2 & $\S$ & $\begin{array}{l}\text { PDB 2bsy, } \\
2 \text { bt } 1\end{array}$ \\
\hline P03196 & gi:141001 & $\begin{array}{l}\text { Membrane glycoprotein gN, part of } \\
\text { the gM-gN complex, part of the } \\
\text { envelope-tegument interaction }\end{array}$ & BLRF1 & M & & $\beta \gamma$ & hcmvUL73 & $\begin{array}{l}\text { Lake \& Hutt-Fletcher } \\
\quad(2004)\end{array}$ & & & \\
\hline P03197 & gi:141002 & Tegument protein & BLRF2 & $\mathrm{T}$ & & $\gamma$ & & Johannsen et al. (2004) & & 轨 & Soluble \\
\hline P12977 & gi:119112 & $\begin{array}{l}\text { EBNA-3A nuclear protein } \\
\text { (EBNA-3), }(-) \text { effect on } \\
\text { transactivator EBNA-2 and cell } \\
\text { cycle, essential for immortaliza- } \\
\text { tion }\end{array}$ & $\begin{array}{l}\text { BLRF3/ } \\
\text { BERF1 }\end{array}$ & $\mathrm{L}$ & $\times$ & & & $\begin{array}{l}\text { Kieff (1996), Waltzer et al. } \\
\text { (1996), Young \& } \\
\text { Rickinson (2004) }\end{array}$ & 1 & $\dagger$ & $\begin{array}{l}\text { No } \\
\text { expression }\end{array}$ \\
\hline P03191 & gi:119098 & $\begin{array}{l}\text { Processivity factor, sliding clamp, } \\
\text { early antigen protein D (EA-D, } \\
\text { polymerase accessory protein) }\end{array}$ & BMRF1 & $\mathrm{R}$ & & $\alpha \beta \gamma$ & UL42 & Tsurumi et al. (1993) & & & \\
\hline P03192 & gi:141066 & $\begin{array}{l}\text { Receptor for cellular integrins, } \\
\text { needed for infection of epithelial } \\
\text { cells, } 10 \mathrm{TM} \text { helices, RGD motif }\end{array}$ & BMRF2 & M & & $\gamma$ & & $\begin{array}{l}\text { Modrow et al. (1992), } \\
\text { Tugizov et al. (2003) }\end{array}$ & & & \\
\hline P03230 & gi:126373 & $\begin{array}{l}\text { Latent membrane protein } 1 \\
\text { (LMP-1), interferes with } \\
\text { signalling, TRAF-binding } \\
\text { through CTAR1 and 2, essential } \\
\text { for immortalization }\end{array}$ & BNLF1 & $\mathrm{L}$ & $\times$ & $\gamma$ & & $\begin{array}{l}\text { Young \& Rickinson } \\
\text { (2004) }\end{array}$ & & & \\
\hline B28918 & gi:23893667 & Potential membrane protein & BNLF2a & $\mathrm{U}$ & & & & $\begin{array}{l}\text { Rivailler et al. (2002), } \\
\quad \text { Farell (2005) }\end{array}$ & & & \\
\hline A28918 & gi:7460898 & Potential gp141 & BNLF2b & $\mathrm{U}$ & & & & $\begin{array}{l}\text { Rivailler et al. (2002), } \\
\text { Farell (2005) }\end{array}$ & & & \\
\hline P03179 & gi:139165 & $\begin{array}{l}\text { Major tegument protein (MTP), } \\
\text { viral surface protein involved in } \\
\text { B lymphocyte binding }\end{array}$ & BNRF1 & $\mathrm{T}$ & & $\gamma$ & & $\begin{array}{l}\text { Johannsen et al. }(2004) \text {, } \\
\text { Lopez et al. }(2005)\end{array}$ & & & \\
\hline P03189 & gi:136893 & $\begin{array}{l}\text { Large tegument protein-binding } \\
\text { protein (LTPBP) }\end{array}$ & BOLF1 & $\mathrm{T}$ & & $\alpha \beta \gamma$ & UL37 & Johannsen et al. (2004) & & & \\
\hline P03187 & gi:139172 & $\begin{array}{l}\text { Minor capsid protein-binding } \\
\text { protein (mCP-BP), Triplex } \\
\text { protein HSV-1 VP19C } \\
\text { homologue }\end{array}$ & BORF1 & $\mathrm{C}$ & & $\gamma$ & UL38 & Johannsen et al. (2004) & & & \\
\hline P03190 & gi:132602 & $\begin{array}{l}\text { Ribonucleoside reductase, large } \\
140 \text { kDa subunit }\end{array}$ & BORF2 & $\mathrm{N}$ & & $\alpha \beta \gamma$ & UL39 & Kieff (1996) & 2 & $\dagger$ & $\begin{array}{l}\text { No } \\
\text { expression }\end{array}$ \\
\hline P03186 & gi:135574 & Large tegument protein (LTP) & BPLF1 & $\mathrm{T}$ & & $\alpha \beta \gamma$ & UL36 & Johannsen et al. (2004) & & & \\
\hline P03209 & gi:115130 & $\begin{array}{l}\text { Transcription activator, } \mathrm{R} \\
\text { transactivator, Rta, dimeric } \\
\text { (TAF50) }\end{array}$ & BRLF1 & $\mathrm{S}$ & & $\gamma$ & & $\begin{array}{l}\text { Hardwick et al. (1988), } \\
\text { Gruffat et al. (1990) }\end{array}$ & 3 & $\ddagger$ & Insoluble \\
\hline Not in DB & Not in DB & $\begin{array}{l}\text { Spliced BRLF1-BZLF1 protein, } \\
\text { repressor of BZLF1, RAZ }\end{array}$ & $\begin{array}{l}\text { BRLF1/ } \\
\text { BZLF1 }\end{array}$ & $\mathrm{S}$ & $\times$ & & & $\begin{array}{l}\text { Manet et al. }(1989) \text {, } \\
\text { Furnari et al. }(1994), \\
\text { Segouffin } \text { et al. }(1996)\end{array}$ & & & \\
\hline Not in DB & Not in DB & $\begin{array}{l}\text { Hypothetical BRLF1-BZLF1 } \\
\text { splice variant }\end{array}$ & $\begin{array}{l}\text { BRLF1/ } \\
\text { BZLF1b }\end{array}$ & $\mathrm{S}$ & $\times$ & & & Farell (2005) & & & \\
\hline P03207 & gi:141395 & $\begin{array}{l}\text { Enhancement of the induction of } \\
\text { the lytic cycle }\end{array}$ & BRRF1 & $\mathrm{S}$ & & $\gamma$ & & $\begin{array}{l}\text { Segouffin-Cariou et al. } \\
\quad(2000), \text { Hong et al. } \\
\quad(2004)\end{array}$ & 1 & $\dagger$ & $\begin{array}{l}\text { No } \\
\text { expression }\end{array}$ \\
\hline P03210 & gi:141396 & $\begin{array}{l}\text { Tegument protein, unknown } \\
\text { function }\end{array}$ & BRRF2 & $\mathrm{T}$ & & $\gamma$ & & Johannsen et al. (2004) & & & \\
\hline P03193 & gi:136937 & $\begin{array}{l}\text { Primase, subunit of the helicase- } \\
\text { primase complex, part of the } \\
\text { replication machinery }\end{array}$ & BSLF1 & $\mathrm{R}$ & & $\alpha \beta \gamma$ & UL52 & Yokoyama et al. (1999) & & $\dagger$ & $\begin{array}{l}\text { No } \\
\text { expression }\end{array}$ \\
\hline Q04360 & gi:1708410 & $\begin{array}{l}\text { mRNA-export factor (EB2, } \\
\text { Mta,SM), mRNA splicing, } \\
\text { interaction with human Spen } \\
\text { proteins, IE63 (ICP27) } \\
\text { homologue }\end{array}$ & $\begin{array}{l}\text { BSLF2/ } \\
\text { BMLF1 }\end{array}$ & $\mathrm{S}$ & $\times$ & $\alpha \beta \gamma$ & UL54 & $\begin{array}{l}\text { Boeckmann et al. }(2003) \text {, } \\
\text { Hiriart et al. }(2005), \\
\text { Swaminathan (2005) }\end{array}$ & 6 & T & $\begin{array}{l}\text { In crystalli- } \\
\text { zation }\end{array}$ \\
\hline P03194 & gi:141432 & $\begin{array}{l}\text { Palmitoylated tegument protein } \\
\qquad(\text { PalmP) }\end{array}$ & BSRF1 & $\mathrm{T}$ & & $\alpha \beta \gamma$ & UL51 & Johannsen et al. (2004) & & & \\
\hline P30119 & gi:267575 & $\begin{array}{l}\text { Capsid maturation, } \\
\text { capsid-associated }\end{array}$ & BTRF1 & $\mathrm{C}$ & & $\alpha \gamma$ & UL21 & Wagenaar et al. (2001) & & & \\
\hline P03233 & gi:136861 & $\begin{array}{l}\text { Portal plug (EC-RF2), capsid- } \\
\text { associated tegument protein, } \\
\text { seals DNA inside capsid }\end{array}$ & BVRF1 & $\mathrm{C}$ & & $\alpha \beta \gamma$ & UL25 & $\begin{array}{l}\text { Sheaffer et al. (2001), } \\
\text { Johannsen et al. (2004) }\end{array}$ & & & \\
\hline
\end{tabular}


Table 1 (continued)

\begin{tabular}{|c|c|c|c|c|c|c|c|c|c|c|c|}
\hline Accession & NCBI & Function & ORF EBV & $\mathrm{F}$ & $\mathrm{S}$ & Occ. & Homologue & Reference & $N$ & $\mathrm{St}$ & Comment \\
\hline P03234 & gi:139231 & Protease/assemblin & BVRF2 & $\mathrm{C}$ & & $\alpha \beta \gamma$ & UL26 & Buisson et al. (2002) & 2 & $\dagger$ & PDB $106 \mathrm{e}$ \\
\hline P03177 & gi:1170666 & Thymidine kinase & BXLF1 & $\mathrm{N}$ & & $\alpha \gamma$ & UL32 & Littler et al. (1986) & 3 & 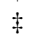 & Insoluble \\
\hline P03231 & gi:138312 & $\begin{array}{l}\text { Glycoprotein gp } 85, \mathrm{gH}, \text { part of } \\
\text { gHgLgp42, fusion }\end{array}$ & BXLF2 & M & & $\alpha \beta \gamma$ & UL22 & $\begin{array}{l}\text { Spear \& Longnecker } \\
\quad(2003), \text { Hutt-Fletcher } \\
(2005)\end{array}$ & & & \\
\hline P03232 & gi:136852 & Nucleoprotein & BXRF1 & $\mathrm{U}$ & & $\alpha \beta \gamma$ & UL24 & Pearson \& Coen (2002) & 2 & $\neq$ & Insoluble \\
\hline P12978 & gi:119111 & $\begin{array}{l}\text { EBNA-2 nuclear protein, } \\
\text { transcription factor, interacts } \\
\text { with RBPJ-K, essential for } \\
\text { immortalization }\end{array}$ & BYRF1 & $\mathrm{L}$ & $x$ & & & $\begin{array}{l}\text { Henkel et al. }(1994) \\
\text { Waltzer } \text { et al. }(1994) \\
\text { Young \& Rickinson } \\
\text { (2004) }\end{array}$ & & & \\
\hline P03206 & gi:115196 & $\begin{array}{l}\text { Trans-activator ZEBRA, origin } \\
\text { binding protein (EB1, Zta), bZip } \\
\text { similar to CCAAT/enhancer } \\
\text { binding protein } \alpha\end{array}$ & BZLF1 & $\mathrm{S}$ & $x$ & $\gamma$ & & $\begin{array}{l}\text { Chevallier-Greco et al. } \\
\text { (1986), Rooney et al. } \\
\text { (1988), Giot et al. } \\
\text { (1991), Petosa et al. } \\
\text { (2006) }\end{array}$ & & & $\begin{array}{l}\text { PDB 2c9n, } \\
2 \mathrm{c} 91\end{array}$ \\
\hline QQBE27 & gi:73982 & $\begin{array}{l}\text { Function unknown, BZLF1 splice } \\
\text { variant }\end{array}$ & BZLF1b & $\mathrm{U}$ & $x$ & & & $\begin{array}{l}\text { Countryman \& Miller } \\
\text { (1985), Farell (2005) }\end{array}$ & & & \\
\hline P03205 & gi:141578 & $\begin{array}{l}\text { gp42, MHC class II binding } \\
\text { protein, part of gHgLgp } 42 \\
\text { complex }\end{array}$ & BZLF2 & M & & $\gamma$ & & $\begin{array}{l}\text { Mullen et al. (2002), } \\
\text { Ressing et al. (2003) }\end{array}$ & & & PDB $1 \mathrm{~kg} 0$ \\
\hline P03235 & gi:140616 & EC-RF4 (ECRF4) protein & ECRF4 & $\mathrm{U}$ & & & & $\begin{array}{l}\text { Rivailler et al. (2002), } \\
\quad \text { Ressing et al. }(2003)\end{array}$ & & & \\
\hline Q8AZJ5 & gi:23893655 & $\begin{array}{l}\text { Protein LF1, contains a dUTPase } \\
\text { like domain, } \gamma \text {-herpes ORF10 } \\
\text { family }\end{array}$ & LF1 & $\mathrm{U}$ & & $\gamma$ & & $\begin{array}{l}\text { Rivailler et al. }(2002), \\
\text { Davison \& Stow (2005), } \\
\text { Farell (2005) }\end{array}$ & & & \\
\hline Q99306 & gi:23893654 & $\begin{array}{l}\text { Protein LF2, contains a dUTPase } \\
\text { like domain, } \gamma \text {-herpes ORF11 } \\
\text { family }\end{array}$ & LF2 & $\mathrm{U}$ & & $\gamma$ & & $\begin{array}{l}\text { Rivailler et al. }(2002), \\
\text { Davison \& Stow (2005), } \\
\text { Farell (2005) }\end{array}$ & & & \\
\hline Not in DB & Not in DB & RK-BARF0, interaction with notch & RK-BARF0 & $\mathrm{S}$ & $x$ & & & $\begin{array}{l}\text { Fries et al. (1997), Kusano } \\
\text { \& Raab-Traub (2001) }\end{array}$ & & & \\
\hline $\mathrm{P} 13285$ & gi:126379 & $\begin{array}{l}\text { LMP-2A, interference with protein } \\
\text { kinase signalling, gene terminal } \\
\text { protein, essential for } \\
\text { immortalization }\end{array}$ & & $\mathrm{L}$ & $x$ & & & $\begin{array}{l}\text { Kieff (1996), Young \& } \\
\text { Rickinson (2004) }\end{array}$ & & & \\
\hline Q8AZK9 & gi:23893578 & $\begin{array}{l}\text { LMP-2B, negative regulator of } \\
\text { LMP-2A }\end{array}$ & & $\mathrm{L}$ & $x$ & & & $\begin{array}{l}\text { Kieff (1996), Young \& } \\
\text { Rickinson (2004) }\end{array}$ & & & \\
\hline
\end{tabular}

$\dagger$ Cloned. $\ddagger$ Expressed. $\S$ Structure solved. $\uparrow$ Purified protein. $\dagger \dagger$ Crystals. $\ddagger$ t Soluble protein.

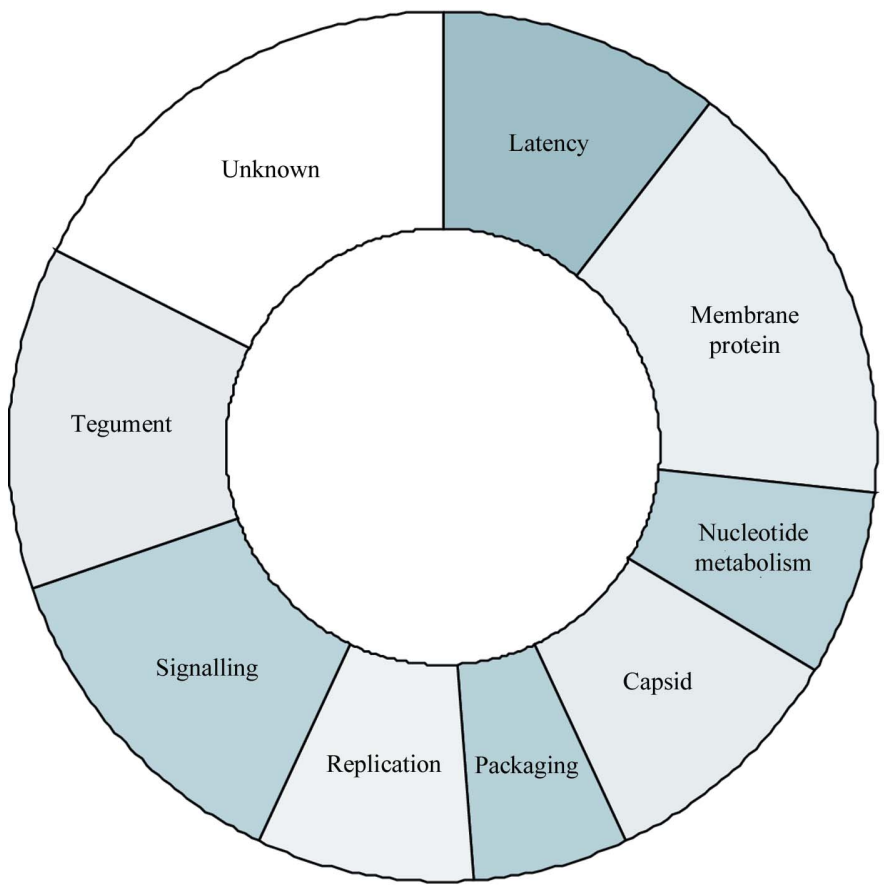

(a)

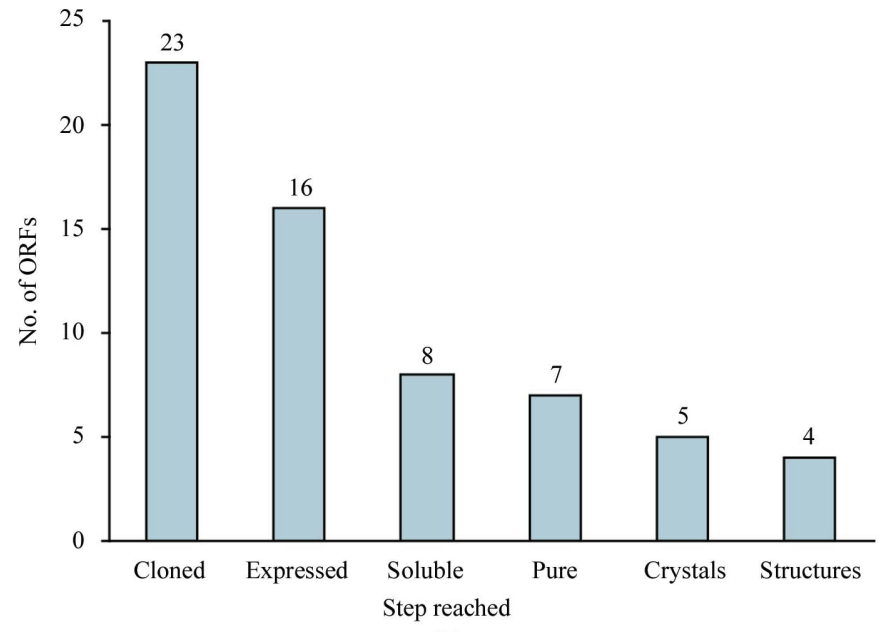

(b)

Figure 1

(a) Classification of the EBV proteins according to function. (b) Outcome for the proteins entering into the structural genomics project. 
Table 2

Crystallographic results.

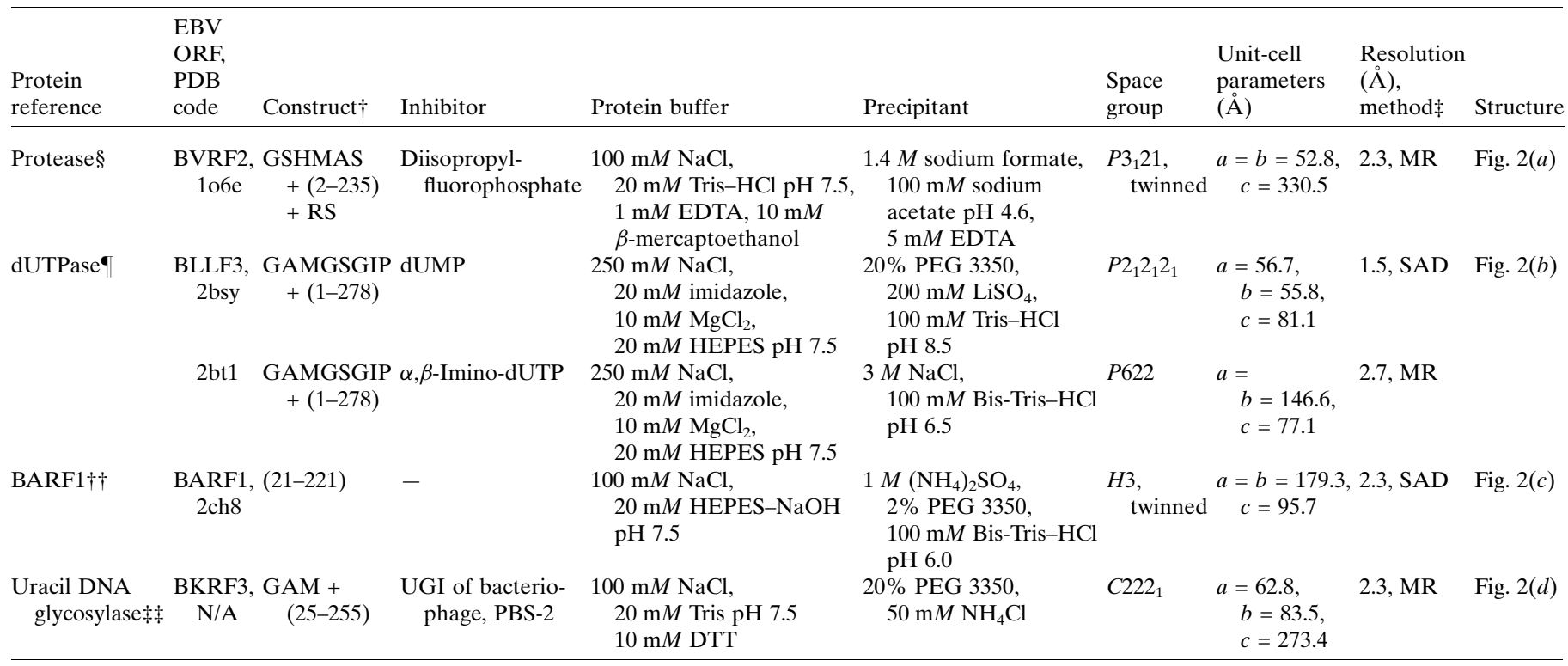

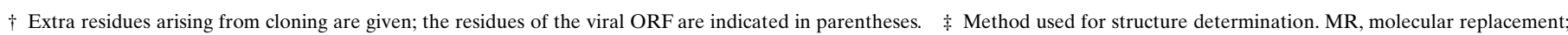
SAD, single-wavelength anomalous dispersion on a heavy-atom derivative. § Buisson et al. (2002). @ Tarbouriech et al. (2005). †† Tarbouriech et al. (2006). 就 Unpublished.

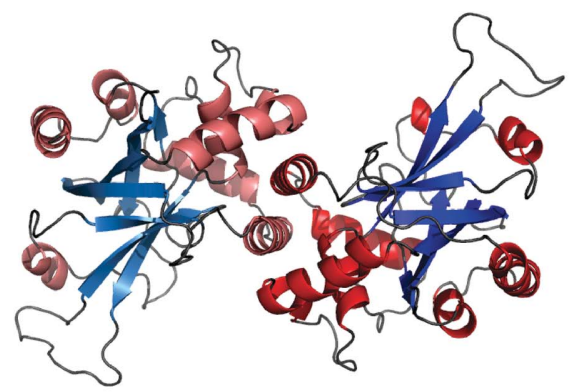

(a)

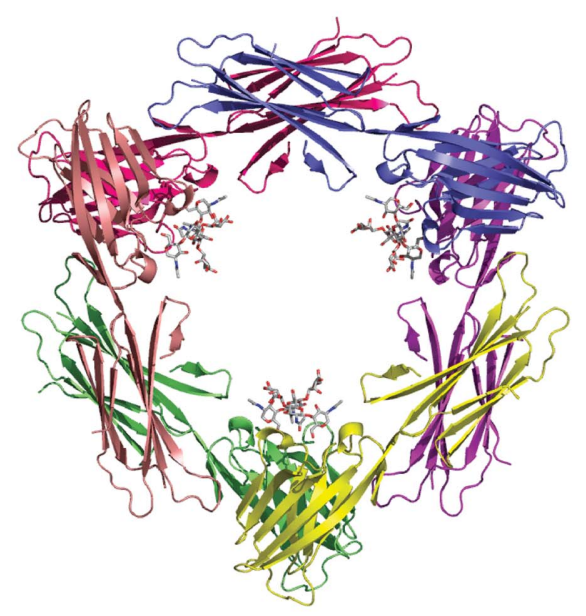

(c)

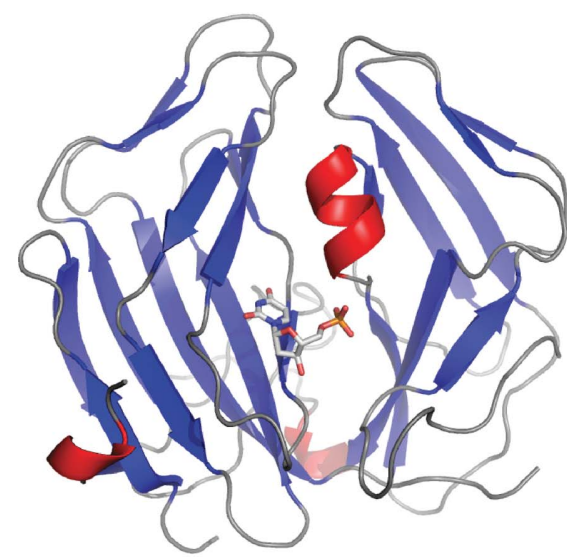

(b)

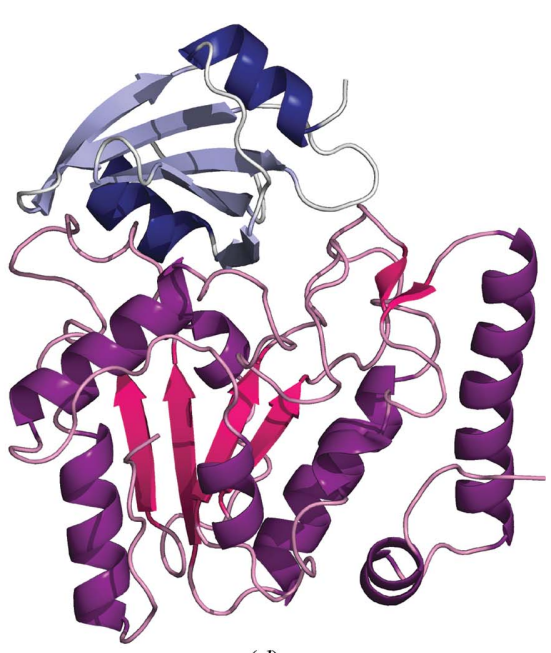

(d)

EBV is composed of an inner capsid that contains the viral double-stranded DNA genome, surrounded by a membrane carrying various surface glycoproteins. Tegument fills the space between the capsid and the membrane. During the latent stage of infection in B-lymphocytes a very limited set of proteins is expressed. The viral DNA forms a circular episome which is associated with the cellular chromosomes and is replicated by the cellular machinery during cell division. After activation, the infection can switch to the lytic cycle, leading to the expression of the full set of viral proteins and production of viral particles. This complex lifestyle utilizes about 86 predicted proteins (Table 1), meaning that EBV has one of the largest genomes of human viruses. The principal viral functions are receptor binding and cell entry, maintenance of latency, nucleotide metabolism, DNA replication and packaging and capsid assembly (Fig. 1a, Table 1). EBV also codes for a number of immune-modulators. Some little-studied proteins shuttle viral particles from the nucleus, the site of viral replication, to the extracellular space and a number of proteins still have no assigned function. With the aim of obtaining insight into

Protein structures (see Table 2). 
the protein functions and in order to identify new drug targets, SPINE (Structural Genomics In Europe) included the structural proteomics of herpesviruses in workpackage 9 (human pathogen targets; see Fogg et al., 2006) and here we report our contribution to this, namely the analysis of a cohort of $23 \mathrm{EBV}$ proteins.

\section{Project design, methods and results}

\subsection{Target annotation}

The project included a major continued effort in protein annotation since the information available in databases [principally SWISS-PROT (Boeckmann et al., 2003) and VIDA (Alba, 2002)] was rather incomplete, in particular for spliced reading frames, or no longer up to date. Our annotation is given in Table 1 with the results on the SPINE targets, together with as much bibliographic information as possible. We identified 86 proteins encoded by the EBV genome. The existence of a few of these remains questionable, owing to alternative splicing. The function of 15 proteins is unknown and could not be inferred from sequence homology or bibliographic information (Table 1, Fig. 1a). In general, little is known about the role of the tegument proteins, even though they have been recently localized unambiguously in the virus particle (Johannsen et al., 2004).

\subsection{Target selection}

As one aim of the project was to obtain structures of potential new drug targets, we first targeted proteins with known enzymatic activity (11 ORFs; Table 1). Next, proteins were ranked according to several predicted properties. Firstly, they were given priority if they had a high predicted secondary structure by the NSP@ server (Deleage et al., 1997), small size and a high stability index according to the ExPASy ProtParam tool (Gasteiger et al., 2005). Known membrane proteins, surface glycoproteins and proteins involved in the packaging mechanism were omitted in order to avoid redundancy with other teams of the SPINE project. Furthermore, we selected against components of known multi-protein assemblies and eliminated proteins containing transmembrane domains using the DAS software (Cserzo et al., 1997) and the TMHMM server (Krogh et al., 2001) available from the ExPASy web site.

\subsection{Cloning and protein production}

We opted for a small-scale parallel approach using simple restriction-based cloning into a vector containing a tobacco etch virus protease (TEV) cleavable $\mathrm{N}$-terminal $\mathrm{His}_{6}$ tag, allowing the targets to be closely followed through purification and crystallization.

2.3.1. Cloning and expression tests. The selected genes were cloned by PCR amplification of EBV DNA extracted from the B95-8 cell line using primers introducing restriction sites at the $5^{\prime}$ and $3^{\prime}$ ends of the gene and ligated into the pPROEX-HTb plasmid (Invitrogen) using standard methods. The PCR products were cloned between $\mathrm{NcoI}$ or BamHI sites as a first choice, EcoRI as a second choice and HindIII or
XhoI sites. The ligated products were directly transformed into Escherichia coli BL21(DE3) GOLD cells (Invitrogen), which were used for both DNA preparation for sequencing and small-scale expression tests. DNA preparation was performed either manually or automatically on the RoBioMol platform at the IBS (Grenoble). Small-scale expression tests used $1 \mathrm{ml} \mathrm{LB}$ media inoculated with single colonies. Protein production was induced with $0.5 \mathrm{~m} M$ isopropyl $\beta$-D-thiogalactoside and continued for $3-5 \mathrm{~h}$ at 310 and $303 \mathrm{~K}$ and overnight at 296 and $289 \mathrm{~K}$. Cells were lysed with BugBuster (Novagen). Protein solubility was checked on SDS-PAGE by loading both the cell extract and the soluble fraction after centrifugation at $18000 \mathrm{~g}$ for $20 \mathrm{~min}$. If soluble protein was not detected, the E. coli strains Rosetta, Origami, BL21 (DE3) STAR (Invitrogen), C41 and C43 (Avidis) were tested with overnight induction at $289 \mathrm{~K}$.

2.3.2. Protein expression and purification. Proteins were produced using either classical LB or an auto-inducible medium (Studier, 2005). Cells were lysed by sonication and cell debris was removed by centrifugation at $30000 \mathrm{~g}$ for $30 \mathrm{~min}$. The supernatant was loaded onto an Ni-NTA (Qiagen) column equilibrated with $20 \mathrm{~m} M$ Tris- $\mathrm{HCl} \mathrm{pH} 7.5$, $100 \mathrm{mM} \mathrm{NaCl}$ and $20 \mathrm{~m} M$ imidazole, washed using the same buffer containing $50 \mathrm{~m} M$ imidazole and eluted at an imidazole concentration of $500 \mathrm{~m} M$. After buffer exchange back to the loading buffer, the protein was incubated overnight at room temperature with a ratio of 1/100 of recombinant His-tagged TEV protease. This was loaded again on an Ni-NTA column and the eluate of this column was concentrated by ultrafiltration and loaded onto a Superdex S75 or S200 gel-filtration column (GE/Amersham), depending on the protein size.

2.3.3. Refolding. When good expression levels of insoluble protein were obtained, refolding was attempted. Following large-scale production with induction at $310 \mathrm{~K}$ for $4-5 \mathrm{~h}$, the protein was purified from inclusion bodies using buffers supplemented with $8 M$ urea. After purification and concentration to $5 \mathrm{mg} \mathrm{ml}^{-1}$, a 20 -fold dilution in refolding buffers was followed by $24 \mathrm{~h}$ incubation at $277 \mathrm{~K}$. Refolding buffers varied in salt concentration $(0$ or $500 \mathrm{mM} \mathrm{NaCl}), \mathrm{pH}$ (Bis-Tris- $\mathrm{HCl}$ $\mathrm{pH} 5$, Tris- $\mathrm{HCl} \mathrm{pH} 7$ or Tris-HCl $\mathrm{pH}$ 9) or divalent cation contents (10 $\mathrm{m} M$ EDTA or $5 \mathrm{~m} M \quad \mathrm{CaCl}_{2} / 5 \mathrm{~m} M \quad \mathrm{MgCl}_{2}$ ), leading to 12 different basic conditions. Samples were centrifuged for $15 \mathrm{~min}$ at $16000 \mathrm{~g}$ and supernatants were assayed for soluble protein either by ammonium sulfate precipitation and SDS-PAGE or by concentration followed by gel filtration.

\subsection{Crystallization}

Proteins were analyzed by dynamic light scattering (Protein Solutions) prior to crystallization. Crystallization screening was carried out at the High Throughput Crystallization Laboratory of the EMBL Grenoble Outstation (HTX Lab). Typically, 576 conditions were tested per sample using a PixSys4200 robot (Cartesian) and the vapour-diffusion method in CrystalQuick (Greiner Bio-One) 96-well sittingdrop crystallization plates with square wells. Drops contained $100 \mathrm{nl}$ protein solution and $100 \mathrm{nl}$ buffer solution. Crystal 
Screen, Crystal Screen II, PEG/Ion Screen, Crystal Screen Lite, Natrix, Membfac, Grid Screens and Index Screen (Hampton Research) were used as well as Clear Strategy Screens (Molecular Dimensions). Crystallization plates were stored and automatically imaged by a CrystalMation robot (RoboDesign) including a RoboIncubator and a Minstrel III module. Successful crystallizations were reproduced and refined manually using $1+1 \mu \mathrm{l}$ hanging drops.

\section{Discussion}

A significant bottleneck in the structure-determination pipeline for EBV proteins was obtaining levels of protein expression (16/23) and soluble protein sufficient for crystallization (7/23; Fig. 1b, Table 1), although the success rate at crystallization was unexpectedly high (5/7). Surprisingly, changing the bacterial strain or expression temperature did not increase soluble expression levels compared with our standard protocol using BL21 cells at $303 \mathrm{~K}$. A bioinformatics analysis using secondary-structure prediction (Deleage et al., 1997) and ClustalW-based alignments (Thompson et al., 1994) only rarely suggested obvious truncations. Perhaps as a consequence of this, modification of the constructs by $\mathrm{N}$-terminal and C-terminal truncations, although attempted for the majority of the studied reading frames (Table 1), was successful in only one case, uracil-DNA glycosylase (UNG), where deletion of the N-terminal 24 residues increased expression levels and led to diffraction-grade crystals. The deleted residues may contain a nuclear localization signal based on sequence identity with human UNG2 (Otterlei et al., 1998). Seven soluble proteins were expressed in E. coli: the EBV protease domain, dUTPase, uracil-DNA glycosidase, BHRF1, BLRF2, BDLF1 and a fragment of BMLF1 (EB2), but the last three proteins were unstable after purification. In the case of the dUTPase, the low solubility of the protein necessitated intensive optimization of purification and crystallization conditions (Tarbouriech et al., 2005). Work on the EBV protease domain predated the SPINE project (Buisson $e t$ al., 2002). Structural determination of BHRF1 was abandoned despite the existence of small crystals when an NMR structure was reported (Huang et al., 2003). BARF1 was obtained through an external collaboration and expressed in eukaryotic cells (de Turenne-Tessier et al., 2005) before entering our structure-determination pipeline. Protein purification using an $\mathrm{N}$-terminal $\mathrm{His}_{6}$ tag together with a TEV protease cleavage site, sometimes including size-exclusion chromatography, reliably produced pure protein for crystallization. In line with other unpublished results in SPINE, refolding from inclusion bodies failed to produce soluble protein from any of the 12 cases. However, we subsequently tested expression in insect cells using baculovirus and obtained three soluble proteins from six ORFs. Overall in SPINE the experience has been that viral proteins tend to be more difficult to express in bacterial systems than prokaryotic proteins (e.g. $27 \%$ of viral proteins were expressed in E. coli compared with $33-77 \%$ of some bacterial proteins; Fogg et al., 2006). It is clear that eukaryotic expression is a real alternative for difficult viral proteins.
Crystallization screening used $200 \mathrm{nl}$ sitting drops dispensed robotically and achieved a very high success rate; however, for proteins except BARF1 this required the addition of enzyme inhibitors (Table 2). Crystallographic details for each EBV structure are given in Table 2 and further details on the structure determinations and refinement have been or will be published elsewhere.

The study described here highlights the particular problems associated with the application of pipeline technologies to difficult proteins. In this case, EBV proteins were poorly suited to bacterial expression systems and success was dependent on a much more individual approach to protein production. Although a simple pipeline approach with standard protocols is unlikely to be universally applicable for structural determination, pipeline components can be extremely effective, exemplified here by the high-throughput nanolitre crystallization platform. This major breakthrough in crystallization screening undoubtedly contributed to the high crystallization rates observed with the soluble EBV proteins.

This work was undertaken as part of the European Union Framework Programme 'Quality of Life and Management of Living Resources', Integrated Project SPINE (Structural Proteomics In Europe), contract No. QLG2-CT-2002-00988. We thank Jean-Marie Seigneurin for providing DNA from the B95.8 cell line and support for the project, Florine Dupeux, Benoit Gallet, José-Antonio Marquez, Martin Rower and Thierry Vernet for the operation of high-throughput facilities at the Grenoble Partnership for Structural Biology (PSB), and Lucy Freeman and Lucie Rivail for work on individual proteins. We are grateful to Henri Gruffat and Tadamasa Ooka for help with the genome annotation.

\section{References}

Alba, M. M. (2002). VIDA Database. http://www.biochem.ucl.ac.uk/ bsm/virus_database/.

Altschul, S. F., Madden, T. L., Schaffer, A. A., Zhang, J., Zhang, Z., Miller, W. \& Lipman, D. J. (1997). Nucleic Acids Res. 25, 3389-3402.

Beard, P. M. \& Baines, J. D. (2004). Virology, 324, 475-482.

Beisel, C., Tanner, J., Matsuo, T., Thorley-Lawson, D., Kezdy, F. \& Kieff, E. (1985). J. Virol. 54, 665-674.

Bellows, D. S., Howell, M., Pearson, C., Hazlewood, S. A. \& Hardwick, J. M. (2002). J. Virol. 76, 2469-2479.

Bochkarev, A., Barwell, J. A., Pfuetzner, R. A., Bochkareva, E., Frappier, L. \& Edwards, A. M. (1996). Cell, 84, 791-800.

Boeckmann, B., Bairoch, A., Apweiler, R., Blatter, M. C., Estreicher, A., Gasteiger, E., Martin, M. J., Michoud, K., O’Donovan, C., Phan, I., Pilbout, S. \& Schneider, M. (2003). Nucleic Acids Res. 31, 365370.

Borza, C. M. \& Hutt-Fletcher, L. M. (1998). J. Virol. 72, 7577-7582. Bowman, B. R., Baker, M. L., Rixon, F. J., Chiu, W. \& Quiocho, F. A. (2003). EMBO J. 22, 757-765.

Buisson, M., Hernandez, J. F., Lascoux, D., Schoehn, G., Forest, E., Arlaud, G., Seigneurin, J. M., Ruigrok, R. W. \& Burmeister, W. P. (2002). J. Mol. Biol. 324, 89-103.

Cabras, G., Decaussin, G., Zeng, Y., Djennaoui, D., Melouli, H., Broully, P., Bouguermouh, A. M. \& Ooka, T. (2005). J. Clin. Virol. 34, 26-34.

Chang, Y. E., Poon, A. P. \& Roizman, B. (1996). J. Virol. 70, 39383946. 
Cheng, Y. C., Chen, J. Y., Hoffmann, P. J. \& Glaser, R. (1980). Virology, 100, 334-338.

Chevallier-Greco, A., Manet, E., Chavrier, P., Mosnier, C., Daillie, J. \& Sergeant, A. (1986). EMBO J. 5, 3243-3249.

Coen, D. M. \& Schaffer, P. A. (2003). Nature Rev. Drug Discov. 2, 278-288.

Countryman, J. \& Miller, G. (1985). Proc. Natl Acad. Sci. USA, 82, 4085-4089.

Cserzo, M., Wallin, E., Simon, I., von Heijne, G. \& Elofsson, A. (1997). Protein Eng. 10, 673-676.

Davison, A. J. \& Stow, N. D. (2005). J. Virol. 79, 12880-12892.

Decaussin, G., Leclerc, V. \& Ooka, T. (1995). J. Virol. 69, 7309-7314.

Deleage, G., Blanchet, C. \& Geourjon, C. (1997). Biochimie, 79, 681-686.

Farell, P. J. (2005). Epstein-Barr Virus, edited by E. S. Robertson, pp. 263-287. Norwich: Caister Academic Press.

Fogg, M. J. et al. (2006). Acta Cryst. D62, 1196-1207.

Fries, K. L., Sculley, T. B., Webster-Cyriaque, J., Rajadurai, P., Sadler, R. H. \& Raab-Traub, N. (1997). J. Virol. 71, 2765-2771.

Furnari, F. B., Zacny, V., Quinlivan, E. B., Kenney, S. \& Pagano, J. S. (1994). J. Virol. 68, 1827-1836.

Gasteiger, E., Hoogland, C., Gattiker, A., Duvaud, S., Wilkins, M. R., Appel, R. D. \& Bairoch, A. (2005). The Proteomics Protocols Handbook, edited by J. M. Walker, pp. 571-607. Totowa, NJ, USA: Humana Press.

Gilligan, K. J., Rajadurai, P., Lin, J. C., Busson, P., Abdel-Hamid, M., Prasad, U., Tursz, T. \& Raab-Traub, N. (1991). J. Virol. 65, 62526259.

Giot, J. F., Mikaelian, I., Buisson, M., Manet, E., Joab, I., Nicolas, J. C. \& Sergeant, A. (1991). Nucleic Acids Res. 19, 1251-1258.

Gong, M., Ooka, T., Matsuo, T. \& Kieff, E. (1987). J. Virol. 61, 499-508.

Gonnella, R., Farina, A., Santarelli, R., Raffa, S., Feederle, R., Bei, R., Granato, M., Modesti, A., Frati, L., Delecluse, H. J., Torrisi, M. R., Angeloni, A. \& Faggioni, A. (2005). J. Virol. 79, 3713-3727.

Gruffat, H., Manet, E., Rigolet, A. \& Sergeant, A. (1990). Nucleic Acids Res. 18, 6835-6843.

Hardwick, J. M., Lieberman, P. M. \& Hayward, S. D. (1988). J. Virol. 62, 2274-2284.

Henkel, T., Ling, P. D., Hayward, S. D. \& Peterson, M. G. (1994). Science, 265, 92-95.

Hiriart, E., Gruffat, H., Buisson, M., Mikaelian, I., Keppler, S., Meresse, P., Mercher, T., Bernard, O. A., Sergeant, A. \& Manet, E. (2005). J. Biol. Chem. 280, 36935-36945.

Hitt, M. M., Allday, M. J., Hara, T., Karran, L., Jones, M. D., Busson, P., Tursz, T., Ernberg, I. \& Griffin, B. E. (1989). EMBO J. 8, 26392651.

Hong, G. K., Delecluse, H. J., Gruffat, H., Morrison, T. E., Feng, W. H., Sergeant, A. \& Kenney, S. C. (2004). J. Virol. 78, 4983-4992.

Hsu, D. H., de Waal Malefyt, R., Fiorentino, D. F., Dang, M. N., Vieira, P., de Vries, J., Spits, H., Mosmann, T. R. \& Moore, K. W. (1990). Science, 250, 830-832.

Huang, Q., Petros, A. M., Virgin, H. W., Fesik, S. W. \& Olejniczak, E. T. (2003). J. Mol. Biol. 332, 1123-1130.

Hutt-Fletcher, L. M. (2005). Epstein-Barr Virus, edited by E. S. Robertson, pp. 359-378. Norwich: Caister Academic Press.

Hwang, J. S. \& Bogner, E. (2002). J. Biol. Chem. 277, 6943-6948.

Johannsen, E., Luftig, M., Chase, M. R., Weicksel, S., CahirMcFarland, E., Illanes, D., Sarracino, D. \& Kieff, E. (2004). Proc. Natl Acad. Sci. USA, 101, 16286-16291.

Kieff, E. (1996). Fields Virology, edited by B. N. Fields, pp. 2343-2396. Philadelphia: Lipincott-Raven.

Krogh, A., Larsson, B., von Heijne, G. \& Sonnhammer, E. L. (2001). J. Mol. Biol. 305, 567-580.

Kusano, S. \& Raab-Traub, N. (2001). J. Virol. 75, 384-395.

Lake, C. M. \& Hutt-Fletcher, L. M. (2000). J. Virol. 74, 11162-11172.

Lake, C. M. \& Hutt-Fletcher, L. M. (2004). Virology, 320, 99106.
Laux, G., Freese, U. K. \& Bornkamm, G. W. (1985). J. Virol. 56, 987-995.

Littler, E., Zeuthen, J., McBride, A. A., Trost Sorensen, E., Powell, K. L., Walsh-Arrand, J. E. \& Arrand, J. R. (1986). EMBO J. 5, 1959-1966.

Lopez, R., Urquiza, M., Patino, H., Suarez, J., Reyes, C., Patarroyo, M. A. \& Patarroyo, M. E. (2005). Biochimie, 87, 985-992.

Mackett, M., Conway, M. J., Arrand, J. R., Haddad, R. S. \& HuttFletcher, L. M. (1990). J. Virol. 64, 2545-2552.

Manet, E., Gruffat, H., Trescol-Biemont, M. C., Moreno, N., Chambard, P., Giot, J. F. \& Sergeant, A. (1989). EMBO J. 8, 1819-1826.

Marschall, M., Stein-Gerlach, M., Freitag, M., Kupfer, R., van den Bogaard, M. \& Stamminger, T. (2002). J. Gen. Virol. 83, 10131023.

Marshall, W. L., Yim, C., Gustafson, E., Graf, T., Sage, D. R., Hanify, K., Williams, L., Fingeroth, J. \& Finberg, R. W. (1999). J. Virol. 73, 5181-5185.

Modrow, S., Hoflacher, B. \& Wolf, H. (1992). Arch. Virol. 127, 379-386.

Mullen, M. M., Haan, K. M., Longnecker, R. \& Jardetzky, T. S. (2002). Mol. Cell, 9, 375-385.

Nealon, K., Newcomb, W. W., Pray, T. R., Craik, C. S., Brown, J. C. \& Kedes, D. H. (2001). J. Virol. 75, 2866-2878.

Newcomb, W. W., Juhas, R. M., Thomsen, D. R., Homa, F. L., Burch, A. D., Weller, S. K. \& Brown, J. C. (2001). J. Virol. 75, 10923-10932.

Otterlei, M., Haug, T., Nagelhus, T. A., Slupphaug, G., Lindmo, T. \& Krokan, H. E. (1998). Nucleic Acids Res. 26, 4611-4617.

Paulsen, S. J., Rosenkilde, M. M., Eugen-Olsen, J. \& Kledal, T. N. (2005). J. Virol. 79, 536-546.

Pearson, A. \& Coen, D. M. (2002). J. Virol. 76, 10821-10828.

Petosa, C., Morand, P., Baudin, F., Moulin, M., Artero, J. B. \& Muller, C. W. (2006). Mol. Cell, 21, 565-572.

Raab-Traub, N. (2005). Epstein-Barr Virus, edited by E. S. Robertson, pp. 71-92. Norwich: Caister Academic Press.

Ressing, M. E., van Leeuwen, D., Verreck, F. A., Gomez, R., Heemskerk, B., Toebes, M., Mullen, M. M., Jardetzky, T. S., Longnecker, R., Schilham, M. W., Ottenhoff, T. H., Neefjes, J., Schumacher, T. N., Hutt-Fletcher, L. M. \& Wiertz, E. J. (2003). Proc. Natl Acad. Sci. USA, 100, 11583-11588.

Reuven, N. B., Willcox, S., Griffith, J. D. \& Weller, S. K. (2004). J. Mol. Biol. 342, 57-71.

Rickinson, A. \& Kieff, E. (1996). Fields Virology, edited by B. N. Fields, Vol. 2, pp. 2397-2446. Philadelphia: Lippincott-Raven.

Rivailler, P., Jiang, H., Cho, Y. G., Quink, C. \& Wang, F. (2002). J. Virol. 76, 421-426.

Robertson, E. S., Ooka, T. \& Kieff, E. D. (1996). Proc. Natl Acad. Sci. USA, 93, 11334-11340.

Rooney, C., Taylor, N., Countryman, J., Jenson, H., Kolman, J. \& Miller, G. (1988). Proc. Natl Acad. Sci. USA, 85, 9801-9805.

Savva, C. G., Holzenburg, A. \& Bogner, E. (2004). FEBS Lett. 563, 135-140.

Segouffin-Cariou, C., Farjot, G., Sergeant, A. \& Gruffat, H. (2000). J. Gen. Virol. 81, 1791-1799.

Segouffin, C., Gruffat, H. \& Sergeant, A. (1996). J. Gen. Virol. 77, $1529-1536$.

Sheaffer, A. K., Newcomb, W. W., Gao, M., Yu, D., Weller, S. K., Brown, J. C. \& Tenney, D. J. (2001). J. Virol. 75, 687-698.

Smith, R. F. \& Smith, T. F. (1989). J. Virol. 63, 450-455.

Sommer, P., Kremmer, E., Bier, S., Konig, S., Zalud, P., Zeppezauer, M., Jones, J. F., Mueller-Lantzsch, N. \& Grasser, F. A. (1996). J. Gen. Virol. 77, 2795-2805.

Spear, P. G. \& Longnecker, R. (2003). J. Virol. 77, 10179-10185.

Strockbine, L. D., Cohen, J. I., Farrah, T., Lyman, S. D., Wagener, F., DuBose, R. F., Armitage, R. J. \& Spriggs, M. K. (1998). J. Virol. 72, 4015-4021.

Studier, F. W. (2005). Protein Expr. Purif. 41, 207234. 
Swaminathan, S. (2005). Epstein-Barr Virus, edited by E. S. Robertson, pp. 631-649. Norwich: Caister Academic Press.

Tarbouriech, N., Buisson, M., Seigneurin, J. M., Cusack, S. \& Burmeister, W. P. (2005). Structure, 13, 1299-1310.

Tarbouriech, N., Ruggiero, F., de Turenne-Tessier, M., Ooka, T. \& Burmeister, W. P. (2006). J. Mol. Biol. 359, 667-678.

Thompson, J. D., Higgins, D. G. \& Gibson, T. J. (1994). Nucleic Acids Res. 22, 4673-4680.

Trus, B. L., Heymann, J. B., Nealon, K., Cheng, N., Newcomb, W. W., Brown, J. C., Kedes, D. H. \& Steven, A. C. (2001). J. Virol. 75, 28792890.

Tsurumi, T., Kobayashi, A., Tamai, K., Daikoku, T., Kurachi, R. \& Nishiyama, Y. (1993). J. Virol. 67, 4651-4658.

Tugizov, S. M., Berline, J. W. \& Palefsky, J. M. (2003). Nature Med. 9 , 307-314.
Turenne-Tessier, M. de, Jolicoeur, P., Middeldorp, J. M. \& Ooka, T. (2005). Virus Res. 109, 9-18.

Wagenaar, F., Pol, J. M., de Wind, N. \& Kimman, T. G. (2001). Vet. Res. 32, 47-54.

Waltzer, L., Logeat, F., Brou, C., Israel, A., Sergeant, A. \& Manet, E. (1994). EMBO J. 13, 5633-5638.

Waltzer, L., Perricaudet, M., Sergeant, A. \& Manet, E. (1996). J. Virol. 70, 5909-5915.

Wei, M. X. \& Ooka, T. (1989). EMBO J. 8, 2897-2903.

Winters, T. A. \& Williams, M. V. (1993). Virology, 195, 315-326.

Yokoyama, N., Fujii, K., Hirata, M., Tamai, K., Kiyono, T., Kuzushima, K., Nishiyama, Y., Fujita, M. \& Tsurumi, T. (1999). J. Gen. Virol. 80, 2879-2887.

Young, L. S. \& Rickinson, A. B. (2004). Nature Rev. Cancer, 4, $757-$ 768. 